\title{
Comparative Studies on Performance of CCC and Preparative RP-HPLC in Separation and Purification of Steroid Saponins from Dioscorea Zingiberensis C.H.Wright
}

\author{
Xinxin Zhang ${ }^{1}$, Jianli Liu ${ }^{1}$, Wenji Sun ${ }^{1}$ and Yoichiro Ito ${ }^{2^{*}}$ \\ ${ }^{1}$ Biomedicine Key Laboratory of Shaanxi Province, Northwest University, 229 Taibai North Road, Xi'an, Shaanxi 710069, China \\ ${ }^{2}$ Laboratory of Bioseparation Technology, Biochemistry and Biophysics Center, National Heart, Lung, and Blood Institute, National Institutes of Health, Bethesda, \\ Maryland, USA \\ *Corresponding author: Yoichiro Ito, Laboratory of Bioseparation Technology, Biochemistry and Biophysics Center, National Heart, Lung, and Blood Institute, National \\ Institutes of Health, Bethesda, Maryland, USA, Tel: +1 (301) 496-1210; Fax: +1 (301) 402-0013; E-mail: zhangxinxin360@126.com
}

Rec date: Dec 29, 2014, Acc date: Feb 19, 2015, Pub date: Feb 25, 2015

Copyright: (C) 2015 Zhang X, et al. This is an open-access article distributed under the terms of the Creative Commons Attribution License, which permits unrestricted use, distribution, and reproduction in any medium, provided the original author and source are credited.

\begin{abstract}
Steroid Saponins from Dioscorea zingiberensis C.H.Wright were separated for the first time using two chromatographic methods for comparison: counter-current chromatography (CCC) coupled with evaporative light scattering detector (ELSD) and preparative reversed phase high-performance liquid chromatography (RP-HPLC) with an ultraviolet detector. Ethyl acetate-n-butanol-methanol-water $(4: 1: 2: 4, \mathrm{v} / \mathrm{v})$ was chosen as the two-phase solvent system for CCC, while the acetonitrile-water (25:75 for the first step and15:85 for the second step, v/v) was used as the mobile phase in the preparative RP-HPLC. The following five steroid Saponins were purified by these two chromatographic methods, in one-step operation by CCC and by two-step operation in preparative RP-HPLC:
\end{abstract}

1) 26-O- $\beta$-D-glucopyranosyl-(25R)-furost- $\triangle 5(6)$-en-3 $\beta, 22 \zeta, 26$-triol-3-O- $\beta$-D-glucopyranosyl-(1 $\rightarrow 3)-\beta-D-$ glucopyranosyl-(1 $\rightarrow 4)$ - $\alpha$-L-rhamnopyranosyl-( $1 \rightarrow 2)-\beta$-D-glucopyranoside $\quad($ compound $\quad A), \quad 2) \quad 26-O-\beta-D-$ glucopyranosyl-(25R)-furost- $\triangle 5(6)$-en-3 $\beta, 22 \zeta, 26$-triol-3-O- $\beta$-D-glucopyranosyl-( $1 \rightarrow 3$ )- $\alpha$-L-rhamnopyranosyl-( $1 \rightarrow 2$ )-

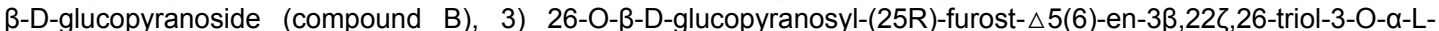
rhamnopyranosyl-(1 $\rightarrow 4)-\beta$-D-glucopyranoside (compound $\quad C$ ), 4) 26-O- $\beta$-D-glucopyranosyl-(25R)-furost- $\Delta 5(6)$, 20(22)-diene-3 $\beta$,26-diol-3-O- $\alpha$-L-rhamnopyranosyl-( $1 \rightarrow 4)$-[ $\beta$-D-glucopyranosyl-( $1 \rightarrow 3)-\beta$-D-glucopyranosyl-( $1 \rightarrow 2)]-\beta$ D-glucopyranoside (compound D) and 5) 26-O- $\beta$-D-glucopyranosyl-(25R)-furost- $\Delta 5(6), 20(22)$-diene-3 $\beta, 26$-diol-3-O$\beta$-D-glucopyranosyl-( $1 \rightarrow 4)$ - $\alpha$-L-rhamnopyranosy- $(1 \rightarrow 2)-\beta$-D-glucopyranoside (compound $E$ ). The purities of these five steroid saponins separated by both methods were over $95 \%$, and structural identification of these compounds was performed by ESI-MS, and 13C NMR. Comparison of these two established approaches revealed that CCC required a longer separation time but with less solvent consumption, whereas preparative RP-HPLC gave a shorter separation time but with higher solvent consumption. These results demonstrated that either of these two methods of different separation mechanism is feasible, economical and efficient for rapid preparative isolation and purification of steroid saponins from Dioscorea zingiberensis C.H.Wright.

Keywords: CCC; Preparative RP-HPLC; Steroid saponins; Dioscorea zingiberensis C.H.Wright

\section{Introduction}

Dioscorea zingiberensis C.H.Wright, a unique plant native in China, is one of the most commonly used raw materials for Chinese Traditional Medicine (CTM) [1]. The steroid saponins, primarily contained in the rhizomes of this plant, are the main bioactive components, and have been applied as a folk treatment for cough, anthrax, rheumarthritis, tumefaction, sprain as well as various cardiac diseases in the TCM for a long time [2-6]. Total steroid saponins extracted from other plants of the Dioscoreaceae family are also widely used in clinic for the treatment of coronary heart disease. For example, Di'aoxinxuekang capsules, containing $35 \%$ of total steroid saponins of Dioscorea nipponica Makino, have been used for the treatment of coronary heart disease for more than 10 years in China [7]. Owing to their diverse bioactivities, much attention has been paid to the separation and purification of steroid saponins in recent years. It is known that typical steroid saponins such as diosgenin contain one or more carbohydrate residues [8]. Due to their similar structures and relatively higher polarity, separation and purification often become difficult by means of the conventional chromatographic methods. In addition, the conventional method, such as column chromatography, needs repeated steps which are tedious, time-consuming, and may lead to contamination problem. Furthermore, the overall yield of these methods is usually lower, because some of these compounds are irreversibly adsorbed onto the solid support during the separation $[9,10]$. Therefore, finding much faster and more efficient methods is of great importance.

With the development of modern separation techniques, countercurrent chromatography (CCC) and preparative reversed-phase highperformance liquid chromatography (RP-HPLC) have been used for isolation and purification of active components from traditional Chinese herbs and other natural products. CCC is a support-free liquid-liquid partition method which eliminates irreversible adsorption of samples onto the solid support, providing a wider range of selection of two-phase solvent systems and yielding high purity and recovery [11-15]. Being an amplification mode of analytic HPLC, preparative RP-HPLC has become a powerful tool due to its shorter 
Citation: Zhang X, Liu J, Sun W, Ito Y (2015) Comparative Studies on Performance of CCC and Preparative RP-HPLC in Separation and Purification of Steroid Saponins from Dioscorea Zingiberensis C.H.Wright. J Steroids Horm Sci 6: 1000.150.

Page 2 of 9

isolation time, excellent efficiency and high recovery [16-19]. Because of these remarkable characteristics, these two chromatographic methods play an important role in current biochemical researches.

In this paper we report for the first time the separation of five steroid saponins from Dioscorea zingiberensis C.H.Wright using two different chromatographic methods, CCC and preparative RP-HPLC.

\section{Experimental}

\section{Apparatus}

Preparative CCC instrument employed in this study was a TBE-300A CCC centrifuge (Tauto Biotech Co., Shanghai, China) equipped with a set of three-multilayer coil separation columns and a 20-ml sample loop. The columns were made of polytetrafluoroethylene (PTFE) tubing of $1.5 \mathrm{~mm} \mathrm{I.D.} \mathrm{with} \mathrm{a} \mathrm{total}$ capacity of $300 \mathrm{ml}$. The $\beta$ values $(\beta=r / R$, where $r$ is the revolution radius or the distance from the coil to the holder shaft, and $\mathrm{R}$ is the revolution radius or the distances between the holder axis and central axis of the centrifuge) ranged from 0.5 at the internal layer to 0.8 at the external layer. The revolution speed of the apparatus was regulated by a speed controller from 0 to $1000 \mathrm{rpm}$, and $850 \mathrm{rpm}$ was used in this study. The solvent was pumped into the column with a model TBP5002 constant flow pump (Tauto Biotech Co. Ltd, Shanghai, China), and continuous effluent was monitored online with an Alltech 800 evaporative light scattering detector. The effluent was collected by the DBS-100 automatic fraction collector (Huxi Analysis Instrument Factory Co. Ltd, Shanghai, China). This software N2000 workstation (Zhejiang University, Hangzhou, China) was used to record the chromatogram.

Preparative RP-HPLC separation was performed on the Alltech equipment system (Alltech Co. Ltd, California, USA) with a high pressure binary 627 HPLC pump, a manual $2 \mathrm{ml}$ sample loop, and a preparative mode Model 500 UV (Chen Airlines Tech Instrument, Tianjin, China) single wavelength absorbance detector $(4.5 \mu \mathrm{m}$ cell $)$. The separation of steroid saponins was carried out on the GRACE Adsorbosphere (Alltech Co. Ltd, California, USA) C18 column ( $250 \mathrm{x}$ $22 \mathrm{~mm}, 10 \mu \mathrm{m})$. Evaluation was made on an Allchrom Plus Sever Workstation, and sample fraction was collected by the DBS-100 automatic fraction collector (Huxi Analysis Instrument Factory Co. Ltd, Shanghai, China).

Analytical HPLC separation was performed using the Waters Alliance 2695 equipment (Waters, Milford, MA, USA) with a vacuum degasser, a high pressure quaternary pump, an autosampler, and an Alltech 2000 evaporative light scattering detector. The analytical chromatogram of steroid saponins was obtained with a Welchrom C18 column $(250 \times 4.6 \mathrm{~mm}, 5 \mu \mathrm{m})$. Evaluation and quantification were made on an Empower Workstation.

Nuclear magnetic resonance (NMR) data were recorded on a Bruker Advance 500 spectrometer (Bruker BioSpin, Rheinstetten, Germany). ESI-MS was performed with Thermo LTQ-XL ion trap mass spectrometer (Thermo Scientific, USA).

\section{Materials}

All organic solvents used for CCC and preparative RP-HPLC were of analytical grade and purchased from Tianjin Chemical Factory (Tianjin, China). Acetonitrile used for HPLC was of HPLC-grade, and water purified in a Milli-Q plus system (Millipore, Madrid, Spain) was double distilled water. The rhizomes of Dioscorea zingiberensis C.H.Wright were provided by Yangtze River Pharmaceutical Industry Co., Ltd (Jiangsu, China).

\section{Preparation of total Steroid Saponins}

Dried raw rhizomes of Dioscorea zingiberensis C.H.Wright $(7 \mathrm{Kg})$ were powdered and extracted with $70 \%$ ethanol for three times. The pooled ethanol extract was evaporated to dryness by a rotary evaporator under reduced pressure, and the residues were redissolved in water and subjected to centrifugation. Then, the supernatant was separated on a D-101 macroporous resin column by eluting with $60 \%$ ethanol. The $60 \%$ ethanol effluent was collected, and concentrated under reduced pressure to provide a syrup which was redissolved in 2 $\mathrm{L}$ of water again and extracted with an equal volume of $\mathrm{n}$-butanol six times successively [20]. The pooled n-butanol extract was concentrated yielding $265 \mathrm{~g}$ of residues. In order to further enrich the target components and remove impurities, the residues of n-butanol extract were separated on the silica gel column (100-160 mesh) by eluting with dichloromethane-methanol-water (70:30:10). The effluent was collected according to the $\mathrm{Rf}$ value between $0.2 \sim 0.5$ on thin layer chromatography (TLC) which was developed with a solvent composed of dichloromethane-methanol-water (65:35:10) and then evaporated at $100{ }^{\circ} \mathrm{C}$ under reduced pressure. Finally, about $40 \mathrm{~g}$ of residues were obtained for subsequent CCC and preparative RP-HPLC separations.

\section{Selection and preparation of two-phase solvent system for CCC}

The two-phase solvent system was selected according to the partition coefficient $(\mathrm{K})$ of each target component. Several kinds of solvent systems were prepared each at different volumes and equilibrated in a separation funnel at room temperature. The $\mathrm{K}$ values were determined by HPLC analysis as follows: a suitable amount of total steroid saponins $(10 \mathrm{mg})$ was added to $4.0 \mathrm{ml}$ of the preequilibrated two-phase solvent system consisted of $2 \mathrm{ml}$ of the upper phase and $2 \mathrm{ml}$ of the lower phase in a $10 \mathrm{ml}$ test tube. The capped test tube was shaken vigorously to thoroughly equilibrate the sample between the two phases. After the equilibration was established, an equal volume $(1.5 \mathrm{ml})$ of each phase was separately transferred into another test tube and evaporated. The residues of each phase were dissolved in an equal volume $(2 \mathrm{ml})$ of methanol and analyzed by HPLC. The $\mathrm{K}$ values were calculated according to the equation: $\mathrm{K}=$ $\mathrm{AU} / \mathrm{AL}$, while $\mathrm{AU}$ and $\mathrm{AL}$ were the peak area of each compound in the upper and the lower phases, respectively. Ethyl acetate-n-butanolmethanol-water $(4: 1: 2: 4, \mathrm{v} / \mathrm{v})$ was finally chosen as the two-phase solvent system. The solvent system was mixed and shaken vigorously to thoroughly equilibrate in a separatory funnel at room temperature, and left over night. Then, the two phases were separated and degassed by sonication for $30 \mathrm{~min}$ before use.

\section{Selection of chromatographic conditions in preparative RP- HPLC}

The preparative conditions for the RP-HPLC, including separation factor, cycling time and sample loadability, were obtained according to the analytical HPLC chromatographic data. From the suitable analytical HPLC condition, the optimum chromatographic condition for the preparative RP-HPLC was determined by adjusting the sample loads. After testing several kinds of solvent systems, acetonitrile-water with the volumes of 25:75 (v/v) and 15:85 (v/v) were selected as the 
Citation: Zhang X, Liu J, Sun W, Ito Y (2015) Comparative Studies on Performance of CCC and Preparative RP-HPLC in Separation and Purification of Steroid Saponins from Dioscorea Zingiberensis C.H.Wright. J Steroids Horm Sci 6: 1000.150.

Page 3 of 9

mobile phase for the first step separation and the second step separation, respectively, while the column packed with the C18 (10 $\mu \mathrm{m}, 100 \AA$ ) particles based on the previous reference was used as the stationary phase. The mobile phase was degassed by sonication for 30 min before use.

\section{Preparation of sample solution}

A $100 \mathrm{mg}$ amount of steroid saponins dissolved in $10 \mathrm{ml}$ of lower phase was used as the sample solution for CCC separation. For RPHPLC separation, $100 \mathrm{mg}$ of steroid saponins dissolved in $2 \mathrm{ml}$ of acetonitrile-water $(25: 75, \mathrm{v} / \mathrm{v})$ was used as sample solution for the first step separation, while $80 \mathrm{mg}$ of total steroid saponin sub-fraction collected from the first step separation was dissolved in $2 \mathrm{ml}$ of acetonitrile-water $(15: 85, \mathrm{v} / \mathrm{v})$ and used as the sample solution for the second step separation.

\section{CCC and preparative RP-HPLC separation procedures}

In the CCC experiment, the head-tail elution mode was adopted. A set of three multilayer coil separation columns with a total capacity of $300 \mathrm{ml}$ was first completely filled with the upper stationary phase at a flow rate of $25 \mathrm{ml} \mathrm{min}^{-1}$. Then the apparatus was rotated at $850 \mathrm{rpm}$ while the lower mobile phase was pumped into the head inlet of the column at a flow rate of $2.0 \mathrm{ml} \mathrm{min}^{-1}$ in an isocratic elution mode. The sample solution was injected through the injection valve, after a mobile phase emerged at the tail outlet which indicated that a steady state hydrodynamic equilibrium was established in the column. By applying a flow splitter, a small fraction of the effluent from the outlet of the column was continuously monitored with an Alltech 800 ELSD detector (the drift tube temperature was $55^{\circ} \mathrm{C}$, and the gas flow rate was $3.0 \mathrm{~L} \mathrm{~min}^{-1}$ ), while the rest of the effluent was collected with an automatic fraction collector set at $5 \mathrm{~min}$ for each test tube. During the experiment, the separation temperature was controlled at $25^{\circ} \mathrm{C}$. After peak fractions A-D were eluted, the centrifuge run was stopped, and the column contents were blown out by nitrogen gas to collect fraction $\mathrm{E}$ that was still remained in the column.

In the preparative RP-HPLC experiment, the entire work was performed on the Alltech equipment system. The GRACE Adsorbosphere C18 column $(250 \times 22 \mathrm{~mm}, 10 \mu \mathrm{m})$ was first entirely equilibrated by the appropriate mobile phase at a flow rate of $16 \mathrm{ml}$ $\mathrm{min}^{-1}$. Then, the sample solution was injected through the $2 \mathrm{ml}$ injection valve, after a stable baseline was recorded by the Allchrom Plus Sever Workstation indicating that a steady state hydrodynamic equilibrium was established in the column. The effluent from the outlet of the column was continuously monitored by the Model 500 $\mathrm{UV}$ at $203 \mathrm{~nm}$, and collected with an automatic fraction collector at 3 min for each test tube. Throughout this experiment, the separation temperature was kept at room temperature. Peak fractions I were obtained in the first step, while fraction I was further separated by the second step yielding fractions A-C.

Peak fractions of CCC and preparative RP-HPLC were each concentrated under reduced pressure and their residues were ready for subsequent analysis.

\section{HPLC analysis of peak fractions from CCC and preparative RP-HPLC}

Purity of each peak fraction from CCC and preparative RP-HPLC separation was determined by analytic HPLC. The analyses were performed with a Welchrom C18 column $(250 \times 4.6 \mathrm{~mm}, 5 \mu \mathrm{m})$ at $25^{\circ} \mathrm{C}$. The mobile phase composed of acetonitrile-water $(30: 70, \mathrm{v} / \mathrm{v})$ was isocratically eluted at a flow rate of $1.0 \mathrm{ml} \mathrm{min}^{-1}$, and continuously monitored by an Alltech 2000 evaporative light scattering detector (the drift tube temperature at $104^{\circ} \mathrm{C}$, and the gas flow rate of $2.8 \mathrm{~L} \mathrm{~min}^{-1}$. The purity of CCC and preparative RP-HPLC fractions was calculated using the area normalization.

\section{Identification of peak fractions from CCC and preparative RP-HPLC}

Identification of the structure of each peak fraction was performed by means of ESI-MS and 13C NMR. The spectra of ESI-MS were obtained by the Thermo LTQ-XL ion trap mass spectrometer, and the spectra of 13C NMR were obtained by the Bruker Advance 500 spectrometer.

\section{Results and Discussion}

\section{CCC and preparative RP-HPLC separation and HPLC analysis}

In CCC, five steroid saponins were obtained with the two-phase solvent system composed of ethyl acetate-n-butanol-methanol-water $(4: 1: 2: 4, \mathrm{v} / \mathrm{v})$ in less than $3.5 \mathrm{~h}$ with the total elution volume of $420 \mathrm{ml}$ in one step separation. This separation yielded $18.2 \mathrm{mg}$ of compound A (fraction was collected during 100-120 min), $22.4 \mathrm{mg}$ of compound B (fraction was collected during 130-148 min), $15.7 \mathrm{mg}$ of compound C (fraction was collected during 160-180 min), $10.9 \mathrm{mg}$ of compound D (fraction was collected during 190-205 min), and $10.2 \mathrm{mg}$ of compound $\mathrm{E}$ (from the column contents) from $100 \mathrm{mg}$ of the crude extract (Figure 1). The retention of the stationary phase was $42 \%$ of the total column capacity after the separation was completed.

In preparative RP-HPLC, the same five steroid saponins were also obtained with the mobile phase of acetonitrile-water (25:75, and 15:85, $\mathrm{v} / \mathrm{v})$ in $1 \mathrm{~h}$ with the total elution volume of $960 \mathrm{ml}$ in two-step separation. Three fractions, I, D and E were obtained in the first step with the mobile phase composed of acetonitrile-water at a volume of 25:75 (v/v). Among those fractions, I was concentrated under reduced pressure and dissolved in suitable solvent which was loaded on the preparative RP-HPLC column and eluted with acetonitrile-water at a volume of 15:85 (v/v). This two-step process yielded $15.7 \mathrm{mg}$ of compound A, $20.5 \mathrm{mg}$ of compound B, $14.2 \mathrm{mg}$ of compound C, 8.5 $\mathrm{mg}$ of compound $\mathrm{D}$ and $8.8 \mathrm{mg}$ of compound $\mathrm{E}$ from $100 \mathrm{mg}$ of the crude extract (Figure 2).

In these two methods both in the reversed elution mode all compounds were eluted in the order of polarity: the most polar compound was eluted first followed by the rest in the order of decreasing polarity. The purities of these five target compounds obtained by these two methods were over $95 \%$. The analytical HPLC chromatogram is shown in Figure 3. 
Citation: Zhang X, Liu J, Sun W, Ito Y (2015) Comparative Studies on Performance of CCC and Preparative RP-HPLC in Separation and Purification of Steroid Saponins from Dioscorea Zingiberensis C.H.Wright. J Steroids Horm Sci 6: 1000.150.

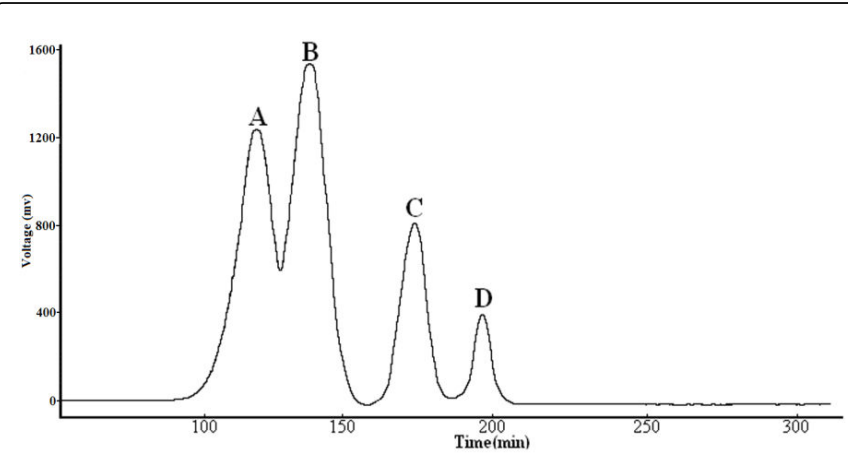

Figure 1: CCC chromatogram of total steroid saponins. Solvent system: ethyl acetate-n-butanol-methanol-water (4:1:2:4, v/v); stationary phase: upper organic phase; mobile phase: lower aqueous phase; flow-rate: $2.0 \mathrm{ml} \mathrm{min}^{-1}$; revolution speed: $850 \mathrm{rpm}$; sample: $100 \mathrm{mg}$ dissolved in $10 \mathrm{ml}$ lower phase; retention of the stationary phase: $42 \%$; Alltech 800 ELSD condition: drift tube temperature: $55^{\circ} \mathrm{C}$; gas flow rate $3.0 \mathrm{~L} \mathrm{~min}^{-1}$.
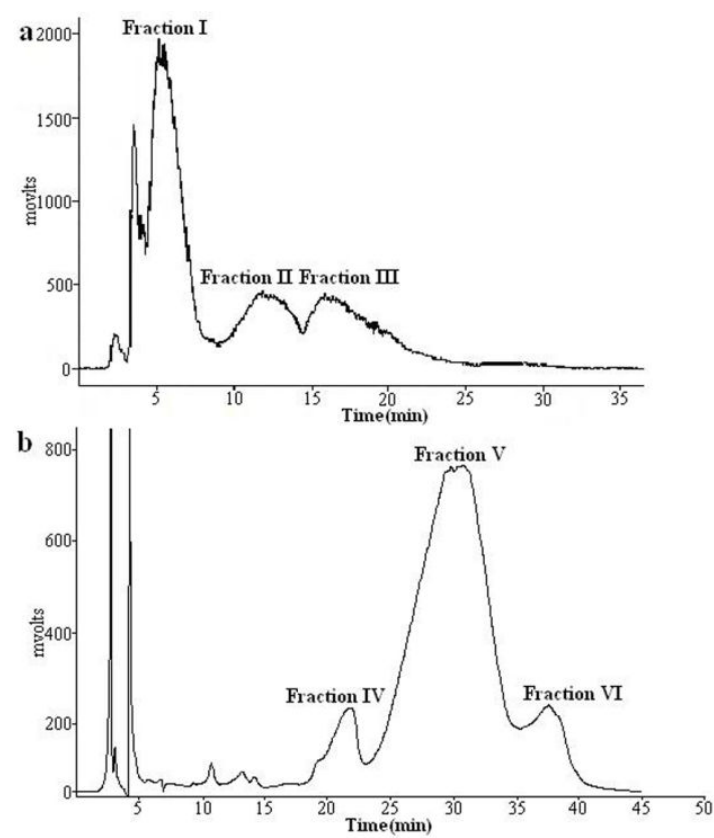

Figure 2: The preparative HPLC chromatograms of total steroid saponins and fraction I. Conditions: The GRACE Adsorbosphere C18 column $(250 \mathrm{~mm}$ x $22 \mathrm{~mm}, 10 \mu \mathrm{m})$; Flow rate: $16 \mathrm{ml} \mathrm{min}^{-1}$; Injection volume: $2 \mathrm{ml}$; Model $500 \mathrm{UV}$ detector wavelength monitoring: $203 \mathrm{~nm}$. (a): Mobile phase: acetonitrile-water (25:75, $\mathrm{v} / \mathrm{v}$ ) in separation total steroid saponins; (b): Mobile phase: acetonitrile-water $(15: 85, \mathrm{v} / \mathrm{v})$ in separation fraction I.

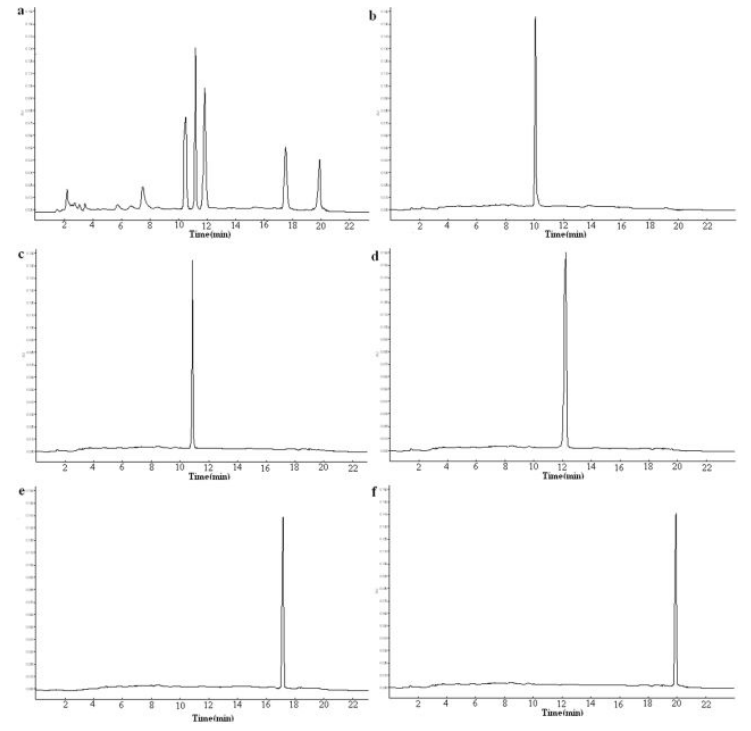

Figure 3: HPLC chromatograms of total saponins, CCC and preHPLC peak fractions. Conditions: column: Welchrom C18 column $(250 \times 4.6 \mathrm{~mm}, 5 \mu \mathrm{m})$; mobile phase: acetonitrile-water $(30: 70, \mathrm{v} / \mathrm{v})$; flow rate: $1 \mathrm{ml} \mathrm{min-1;} \mathrm{Alltech} 2000$ ELSD condition: drift tube temperature: $104^{\circ} \mathrm{C}$; gas flow rate $2.8 \mathrm{~L} \mathrm{~min}-1$; column temperature: $25^{\circ} \mathrm{C}$; injection volume: $10 \mu \mathrm{L}$. (a): Total steroid saponins; (b): Compounds A; (c): Compounds B; (d): Compounds C; (e): Compounds D; (f): Compounds E.

\section{Structure Identification of purified compounds.}

The structures of five target compounds were confirmed as the steroid saponins shown in Figure 4 by means of the modern spectroscopic techniques, including ESI-MS shown in Figure 5 and 13C NMR in Table 1.

Data of compound A: ESI-MS(m/z): $1249([\mathrm{M}+\mathrm{Na}]+)$, molecular formula: C57H94O28. Compared with Ref [21], compound A was identified as $26-\mathrm{O}-\beta$-D-glucopyranosyl-(25R)-furost- $\Delta 5(6)$-en- $3 \beta, 22 \zeta$, 26 -triol-3-O- $\beta$-D-glucopyranosyl-( $1 \rightarrow 3)-\beta$-D-glucopyranosyl- $(1 \rightarrow 4)$ - $\alpha$ L-rhamnopyranosyl- $(1 \rightarrow 2)-\beta$-D-glucopyranoside.

Data of compound B: ESI-MS(m/z): $1087([\mathrm{M}+\mathrm{Na}]+)$, molecular formula: C51H84O23. Compared with Ref $[11,21]$, compound B was identified as $26-O-\beta$-D-glucopyranosyl-(25R)-furost- $\Delta 5(6)$-en- $3 \beta, 22 \zeta$, 26 -triol-3-O- $\beta$-D-glucopyranosyl-( $1 \rightarrow 3)$ - $\alpha$-L-rhamnopyranosyl- $(1 \rightarrow 2)$ $\beta$-D-glucopyranoside.

Data of compound C: ESI-MS(m/z): $925([\mathrm{M}+\mathrm{Na}]+)$, molecular formula: C45H74O18. Compared with Ref [22], compound $\mathrm{C}$ was identified as $26-O-\beta$-D-glucopyranosyl-(25R)-furost- $\Delta 5(6)$-en- $3 \beta, 22 \zeta$, 26-triol-3-O- $\alpha$-L-rhamnopyranosyl-( $1 \rightarrow 4)-\beta$-D-glucopyranoside.

Data of compound D: ESI-MS(m/z): $1231.67([\mathrm{M}+\mathrm{Na}]+)$, molecular formula: C57H92O27. Compared with Ref [22], compound D was identified as $26-\mathrm{O}-\beta$-D-glucopyranosyl-(25R)-furost- $\Delta 5(6), 20(22)$ diene-3 $\beta$,26-diol-3-O- $\alpha$-L-rhamnopyranosyl- $(1 \rightarrow 4)-[\beta-D$ glucopyranosyl- $(1 \rightarrow 3)-\beta$-D-glucopyranosyl- $(1 \rightarrow 2)]-\beta$-Dglucopyranoside. 
Citation: Zhang X, Liu J, Sun W, Ito Y (2015) Comparative Studies on Performance of CCC and Preparative RP-HPLC in Separation and Purification of Steroid Saponins from Dioscorea Zingiberensis C.H.Wright. J Steroids Horm Sci 6: 1000.150.

Page 5 of 9

Data of compound E: ESI-MS(m/z): 1069.33([M+Na]+), molecular formula: $\mathrm{C} 51 \mathrm{H} 82 \mathrm{O} 22$; compound $\mathrm{E}$ was identified as $26-\mathrm{O}-\beta-\mathrm{D}$ -
glucopyranosyl-(25R)-furost- $\Delta 5(6), 20(22)$-diene-3 $\beta, 26$-diol-3-O- $\beta$-Dglucopyranosyl- $(1 \rightarrow 4)-\alpha-L-$ rhamnopyranosy- $(1 \rightarrow 2)-\beta$-Dglucopyranoside.

\begin{tabular}{|c|c|c|c|c|c|c|c|c|c|}
\hline \multicolumn{10}{|c|}{ Compounds } \\
\hline \multicolumn{2}{|l|}{ Compound A } & \multicolumn{2}{|c|}{ Compound B } & \multicolumn{2}{|c|}{ Compound C } & \multicolumn{2}{|c|}{ Compound D } & \multicolumn{2}{|l|}{ Compound E } \\
\hline \multicolumn{2}{|c|}{$1249[\mathrm{M}+\mathrm{Na}]+$} & \multicolumn{2}{|c|}{1087 [M+Na]+ } & \multicolumn{2}{|l|}{$925[\mathrm{M}+\mathrm{Na}]+$} & \multicolumn{2}{|c|}{$1231.67[\mathrm{M}+\mathrm{Na}]+$} & \multicolumn{2}{|c|}{$1069.33[\mathrm{M}+\mathrm{Na}]+$} \\
\hline Aglycone & Sugar Moiety & Aglycone & Sugar Moiety & Aglycone & Sugar Moiety & Aglycone & Sugar Moiety & Aglycone & Sugar Moiety \\
\hline (ppm) & (ppm) & (ppm) & (ppm) & (ppm) & $(\mathrm{ppm})$ & (ppm) & (ppm) & (ppm) & (ppm) \\
\hline $37.4(\mathrm{C}-1)$ & $100.9\left(\right.$ Glu'$\left.^{\prime}-1\right)$ & $37.2(\mathrm{C}-1)$ & $100.1\left(\right.$ Glu'-1) $^{\prime}$ & $37.8(C-1)$ & $102.3\left(\right.$ Glu'$\left.^{\prime}-1\right)$ & $37.0(\mathrm{C}-1)$ & 100.3 (Glu'-1) & $37.5(\mathrm{C}-1)$ & 99.9 (Glu'-1) \\
\hline $30.5(C-2)$ & $77.2\left(\mathrm{Glu}^{\prime}-2\right)$ & 31.5 (C-2) & 77.3 (Glu'-2) & $30.2(C-2)$ & 73.1 (Glu'-2) & $31.4(\mathrm{C}-2)$ & 81.5 (Glu'-2) & 30.1 (C-2) & 77.2 (Glu'-2) \\
\hline 78.6 (C-3) & 77.0 (Glu'-3) & $71.7(\mathrm{C}-3)$ & 88.7 (Glu'-3) & 78.6 (C-3) & 73.5 (Glu'-3) & $71.6(\mathrm{C}-3)$ & 76.2 (Glu'-3) & $78.0(\mathrm{C}-3)$ & 77.7 (Glu'-3) \\
\hline $38.8(C-4)$ & 82.1 (Glu'-4) & 42.5 (C-4) & 69.9 (Glu'-4) & 39.9 (C-4) & 72.2 (Glu'-4) & 42.5 (C-4) & 78.6 (Glu'-4) & 38.9 (C-4) & $82.1\left(G \mid u^{\prime}-4\right)$ \\
\hline $141.3(C-5)$ & $78.4($ Glu'-5) & $140.2(C-5)$ & 78.0 (Glu'-5) & $141.4(C-5)$ & 74.6 (Glu'-5) & $140.5(C-5)$ & 77.4 (Glu'-5) & $140.7(C-5)$ & 76.2 (Glu'-5) \\
\hline $122.5(\mathrm{C}-6)$ & 62.9 (Glu'-6) & $121.9(\mathrm{C}-6)$ & $62.1($ Glu'-6) & $121.5(\mathrm{C}-6)$ & 69.2 (Glu'-6) & $121.0(\mathrm{C}-6)$ & $61.6($ Glu'-6) & $121.8(\mathrm{C}-6)$ & 62.5 (Glu'-6) \\
\hline 32.4 (C-7) & 102.0 (Rha'-1) & 32.1 (C-7) & 101.1 (Rha'-1) & 32.4 (C-7) & 105.2 (Glu"-1) & 32.0 (C-7) & 101.7 (Rha'-1) & 32.4 (C-7) & 101.8 (Rha'-1) \\
\hline $30.9(\mathrm{C}-8)$ & 72.4 (Rha'-2) & 31.7 (C-8) & 72.0 (Rha'-2) & $31.2(\mathrm{C}-8)$ & 75.7 (Glu"-2) & $31.2(\mathrm{C}-8)$ & 72.8 (Rha'-2) & $31.4(\mathrm{C}-8)$ & 72.5 (Rha'-2) \\
\hline 49.9 (C-9) & 72.1 (Rha'-3) & $49.5(C-9)$ & 72.2 (Rha'-3) & 50.7 (C-9) & 78.5 (Glu"-3) & $50.3(C-9)$ & 72.7 (Rha'-3) & $50.3(C-9)$ & 72.7 (Rha'-3) \\
\hline $37.5(\mathrm{C}-10)$ & 74.2 (Rha'-4) & $36.1(\mathrm{C}-10)$ & 73.5 (Rha'-4) & $37.2(\mathrm{C}-10)$ & 71.2 (Glu"-4) & $36.4(C-10)$ & 74.1 (Rha'-4) & $37.1(\mathrm{C}-10)$ & 74.1 (Rha'-4) \\
\hline $21.2(\mathrm{C}-11)$ & 69.6 (Rha'-5) & $20.5(C-11)$ & 69.8 (Rha'-5) & $21.2(\mathrm{C}-11)$ & 78.3 (Glu"-5) & $20.7(C-11)$ & 69.4 (Rha'-5) & $21.2(\mathrm{C}-11)$ & 69.5 (Rha'-5) \\
\hline $40.8(\mathrm{C}-12)$ & 18.2 (Rha'-6) & $39.4(C-12)$ & $18.8\left(\right.$ Rha'$\left.^{\prime}-6\right)$ & $40.9(C-12)$ & 63.5 (Glu"-6) & $39.7(C-12)$ & 18.9 (Rha'-6) & $39.6(\mathrm{C}-12)$ & 18.7 (Rha'-6) \\
\hline $41.5(\mathrm{C}-13)$ & 105.7 (Glu"-1) & $41.9(\mathrm{C}-13)$ & 103.1 (Glu"-1) & $40.5(C-13)$ & 100.3 (Rha'-1) & $40.0(C-13)$ & 104.3 (Glu"-1) & $43.4(C-13)$ & 104.9 (Glu"-1) \\
\hline $56.8(\mathrm{C}-14)$ & 88.1 (Glu"-2) & $56.1(\mathrm{C}-14)$ & 74.0 (Glu"-2) & $56.7(\mathrm{C}-14)$ & 78.7 (Rha'-2) & $56.6(\mathrm{C}-14)$ & 73.5 (Glu"-2) & $54.9(\mathrm{C}-14)$ & 78.6 (Glu"-2) \\
\hline 32.1 (C-15) & 74.6 (Glu"-3) & $31.2(C-15)$ & 77.5 (Glu"-3) & $32.7(C-15)$ & 78.9 (Rha'-3) & $31.6(C-15)$ & 88.2 (Glu"-3) & 34.5 (C-15) & 71.7 (Glu"-3) \\
\hline $81.2(\mathrm{C}-16)$ & 69.2 (Glu"-4) & $81.0(C-16)$ & 71.9 (Glu"-4) & $81.4(C-16)$ & 62.5 (Rha'-4) & $80.8(C-16)$ & 69.7 (Glu"-4) & $84.4(C-16)$ & 78.5 (Glu"-4) \\
\hline $63.8(\mathrm{C}-17)$ & 78.9 (Glu"-5) & $62.5(\mathrm{C}-17)$ & 78.3 (Glu"-5) & $64.2(\mathrm{C}-17)$ & 79.1 (Rha'-5) & $62.3(\mathrm{C}-17)$ & 77.6 (Glu"-5) & $64.5(\mathrm{C}-17)$ & 62.8 (Glu"-5) \\
\hline $16.7(\mathrm{C}-18)$ & 61.1 (Glu"-6) & $16.4(C-18)$ & 60.3 (Glu"-6) & $16.8(C-18)$ & $18.2($ Rha'-6) & $16.5(\mathrm{C}-18)$ & 61.8 (Glu"-6) & $14.1(\mathrm{C}-18)$ & 61.8 (Glu"-6) \\
\hline 20.0 (C-19) & 105.2 (Glu"'-1) & $19.1(\mathrm{C}-19)$ & 100.2 (Glu"'-1) & $19.9(C-19)$ & & $19.7(\mathrm{C}-19)$ & 105.2 (Glu"'-1) & $19.4(\mathrm{C}-19)$ & 105.2 (Glu"'-1) \\
\hline $40.9(\mathrm{C}-20)$ & 75.4 (Glu"'-2) & $41.4(\mathrm{C}-20)$ & 78.4 (Glu"'-2) & $41.5(\mathrm{C}-20)$ & & $41.6(C-20)$ & 75.4 (Glu"'-2) & 104.9 (C-20) & 75.0 (Glu"'-2) \\
\hline $16.6(\mathrm{C}-21)$ & 78.3 (Glu"'-3) & $14.8(\mathrm{C}-21)$ & 91.3 (Glu"'-3) & $16.2(\mathrm{C}-21)$ & & $14.3(\mathrm{C}-21)$ & 78.3 (Glu"'-3) & $11.8(\mathrm{C}-21)$ & 78.6 (Glu"'-3) \\
\hline 110.7 (C-22) & 71.1 (Glu"'-4) & $108.9(\mathrm{C}-22)$ & 69.2 (Glu"'-4) & $110.7(\mathrm{C}-22)$ & & $109.3(\mathrm{C}-22)$ & 71.8 (Glu"'-4) & 152.5 (C-22) & 71.2 (Glu"'-4) \\
\hline $36.8(\mathrm{C}-23)$ & 62.3 (Glu"'-5) & $31.3(\mathrm{C}-23)$ & 62.6 (Glu"'-5) & $37.1(\mathrm{C}-23)$ & & $31.6(\mathrm{C}-23)$ & 78.4 (Glu"'-5) & $23.7(\mathrm{C}-23)$ & 78.5 (Glu"'-5) \\
\hline $28.5(\mathrm{C}-24)$ & 78.5 (Glu"'-6) & $28.4(\mathrm{C}-24)$ & 61.7 (Glu"'-6) & $28.4(C-24)$ & & $28.6(C-24)$ & 63.3 (Glu"'-6) & $31.4(\mathrm{C}-24)$ & 61.9 (Glu"'-6) \\
\hline 34.7 (C-25) & 105 (Glu"'-1) & $30.1(\mathrm{C}-25)$ & & $34.1(\mathrm{C}-25)$ & & $30.1(\mathrm{C}-25)$ & 106.3 (Glu"'"-1) & $33.5(\mathrm{C}-25)$ & \\
\hline $75.6(\mathrm{C}-26)$ & 75.1 (Glu"'"-2) & 66.9 (C-26) & & $75.2(\mathrm{C}-26)$ & & $66.8(C-26)$ & 75.7 (Glu"'"-2) & 74.9 (C-26) & \\
\hline \multirow{3}{*}{$17.8(\mathrm{C}-27)$} & 78.2 (Glu"'"-3) & \multirow{3}{*}{$18.4(C-27)$} & & \multirow{3}{*}{$17.8(\mathrm{C}-27)$} & & \multirow{3}{*}{$17.2(\mathrm{C}-27)$} & 78.6 (Glu"'"-3) & \multirow{3}{*}{$17.3(\mathrm{C}-27)$} & \\
\hline & 71.7 (Glu'"'-4) & & & & & & 71.9 (Glu"'"-4) & & \\
\hline & 78.4 (Glu"'--5) & & & & & & 78.7 (Glu"'--5) & & \\
\hline
\end{tabular}


Citation: Zhang X, Liu J, Sun W, Ito Y (2015) Comparative Studies on Performance of CCC and Preparative RP-HPLC in Separation and Purification of Steroid Saponins from Dioscorea Zingiberensis C.H.Wright. J Steroids Horm Sci 6: 1000.150.

Page 6 of 9

\begin{tabular}{|l|l|l|l|l|l|l|l|l|}
\hline & 62.4 (Glu'"'-6) & & & & & & 62.6 (Glu"'-6) & \\
\hline
\end{tabular}

Table 1: The corresponding MS and carbon data of five compounds by 13C NMR method.

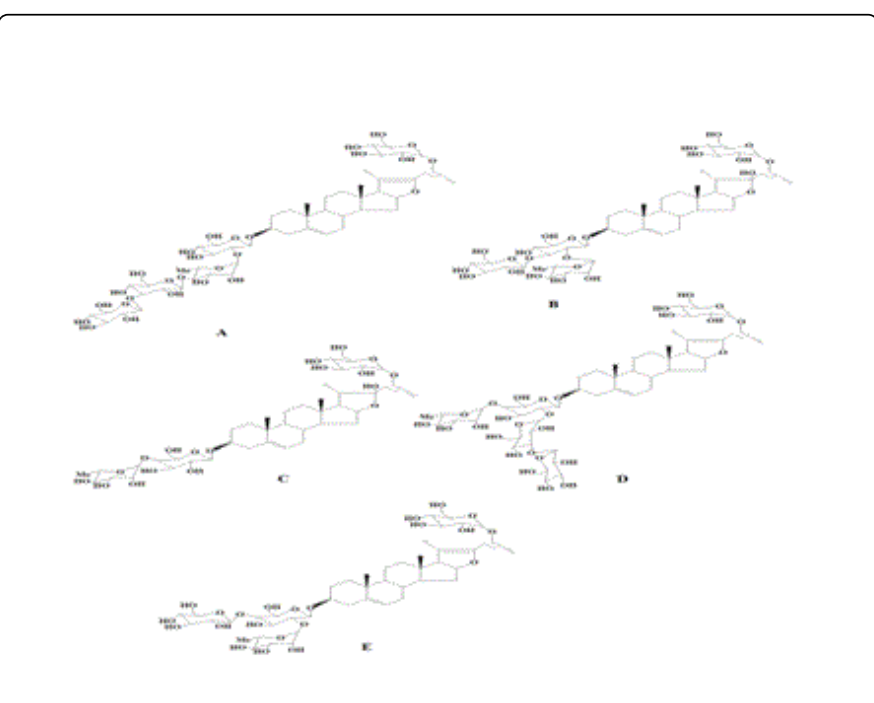

Figure 4: Chemical structures of compounds from Dioscorea zingiberensis C.H.Wright. (A): Compound A; (B): Compound B; (C): Compound C; (D): Compound D; (E): Compound E.

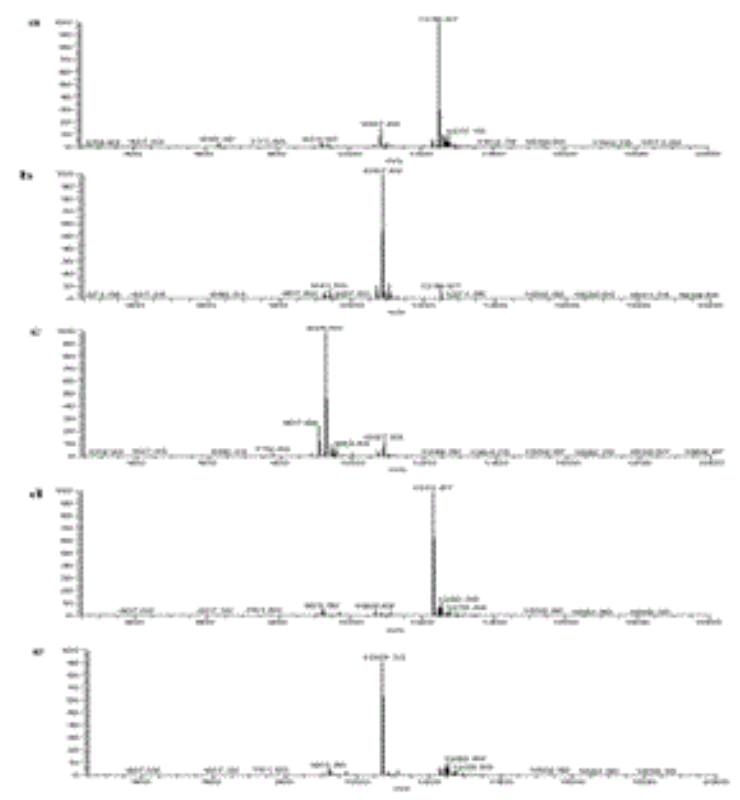

Figure 5: ESI-MS chromatograms of five compounds. (a): Compound A; (b): Compound B; (c): Compound C; (d): Compound D; (e): Compound E.

\section{Optimization of the conditions of CCC and preparative RP- HPLC}

In the CCC separation, the first step for selecting a suitable twophase solvent system requires almost $90 \%$ of the entire process of separation. The suitable $\mathrm{K}$ values for CCC are in a range of 0.5-2 which gives an efficient separation within a reasonable run time. A smaller $\mathrm{K}$ value would elute the solute peaks near the solvent front with low resolution, while a larger $\mathrm{K}$ value tends to give better resolution but with broader and more dilute peaks due to a longer elution time $[23,24]$. Since the steroid saponins in the rhizomes of Dioscorea zingiberensis C.H.Wright contain some carbohydrates, these saponins have comparatively high polarity and satisfactory solubility in hydrophilic solvents. In order to distribute the target compounds between the two phases, both phases must have certain polarity. In the present experiment, various two-phase solvent systems each at different volumes were tested, and the $\mathrm{K}$ values of the target compounds in these solvent systems are summarized in Table 2. Finally, the two phase solvent system composed of ethyl acetate-nbutanol-methanol-water at a volume of 4:1:2:4 $(\mathrm{v} / \mathrm{v} / \mathrm{v} / \mathrm{v})$ was selected as the two-phase solvent system for CCC separation. Although the same solvent system at the ratio of 4:2:2:4 (v/v/v/v) exhibited a better retention of stationary phase of $45 \%$ than the former one, it looked like inappropriate when considered the $\mathrm{K}$ value of compound $\mathrm{E}$, which led to a long separation and dilute as well as broad peak with much solvent waste according to the gold's rules [24]. Therefore, the solvent in the current study was used.

In a preparative RP-HPLC separation, finding suitable lab-scale preparative conditions from the analytical HPLC chromatographic data is the most challenging work in the whole experiment [25]. The preparative chromatographic data should be optimized for faster production rate and higher purity. The production rate depends mainly on the cycling time, whereas the purity is determined by the following two factors, i.e., the resolution and the sample saturation capacity on the column. The cycling time and the resolution can be calculated from the analytical scale chromatographic data, while the sample saturation capacity is only determined by performing overloading experiments or by measuring the equilibrium adsorption isotherms when there is no reference available. The cycling time should be neither too long nor too short. Longer cycling time would result in lower efficiency and consumption of abundant solvent while shorter cycling time couldn't give enough peak resolution of the target compounds. The sample loading capacity should be tested according to the peak resolution where separation factor of approximately 1.5 will produce complete resolution between the two peaks. Based on the previous reference, the column packed with reversed-phase silica gel C18 particle was used as stationary phase, and the mobile phase consisted of acetonitrile-water with thesis of 25:75 (v/v) and 15:85 $(\mathrm{v} / \mathrm{v})$ were used in preparative RP-HPLC. 
Citation: Zhang X, Liu J, Sun W, Ito Y (2015) Comparative Studies on Performance of CCC and Preparative RP-HPLC in Separation and Purification of Steroid Saponins from Dioscorea Zingiberensis C.H.Wright. J Steroids Horm Sci 6: 1000.150.

\begin{tabular}{|c|c|c|c|c|c|c|c|}
\hline \multirow{2}{*}{$\begin{array}{l}\text { Two-phase } \\
\text { solvent systems }\end{array}$} & \multirow{2}{*}{ Ratio(v/v) } & \multirow{2}{*}{$\begin{array}{l}\text { The final } \\
\text { retention of stationary phase }\end{array}$} & & & \multicolumn{3}{|l|}{ K } \\
\hline & & & A & B & C & D & $\mathrm{E}$ \\
\hline Chloroform-methanol-water & 4:03:02 & - & 22.2 & 132.89 & 25.45 & 35.1 & 37.2 \\
\hline Chloroform-n-butanol-methanol-water & $4: 0.2: 3: 2$ & - & 136.4 & 27.5 & 14.2 & 33.1 & 35.9 \\
\hline n-hexane-ethyl acetate-methanol-water & 1:1:1:1 & - & - & - & - & - & - \\
\hline Ethyl acetate-n-butanol-water & 4:01:05 & - & 0.16 & 0.02 & 0.08 & 0.32 & 0.41 \\
\hline Ethyl acetate-n-butanol-methanol-water & $4: 1: 0.5: 6$ & - & 0.21 & 0.04 & 0.14 & 0.41 & 0.53 \\
\hline Ethyl acetate-n-butanol-methanol-water & 8:0.5:2:4 & $28 \%$ & 0.28 & 0.1 & 0.19 & 0.55 & 0.72 \\
\hline Ethyl acetate-n-butanol-methanol-water & $7: 0.5: 2: 4$ & $30 \%$ & 0.32 & 0.14 & 0.24 & 0.84 & 1.03 \\
\hline Ethyl acetate-n-butanol-methanol-water & $6: 0.5: 2: 4$ & $32 \%$ & 0.4 & 0.21 & 0.54 & 1.03 & 1.52 \\
\hline Ethyl acetate-n-butanol-methanol-water & 4:1:2:4 & $42 \%$ & 0.49 & 0.98 & 1.23 & 1.58 & 1.97 \\
\hline Ethyl acetate-n-butanol-methanol-water & $4: 2: 2: 4$ & $45 \%$ & 0.53 & 1.15 & 1.74 & 1.98 & 2.35 \\
\hline
\end{tabular}

Table 2: Comparison of CCC and preparative RP-HPLC.

\section{Comparison of CCC and preparative RP-HPLC separations}

CCC is a recently developed liquid-liquid partition chromatography without solid support giving a choice of various two-phase solvent systems, while the preparative RP-HPLC is a traditional liquid-solid chromatography with high efficiency and high recovery with a column containing a wide range of high efficiency packing material. Therefore, there are a number of differences in their performance between them as described in Table 3. Some performance parameters of these two different approaches are summarized in Table 4, among which some differ greatly. These differences are mainly derived from the different volumes of active stationary phase available in each separation method. The stationary phase in CCC is a liquid which typically comprises $75 \%$ or more of the column volume, and the lack of a solid support means that this entire volume is accessible to solute. This contrasts with the relatively low active stationary phase volume of RPHPLC supports and CCC allows the injection of up to $10 \%$ of the column volume without chromatographic disturbance.

It is generally recognized that steroid saponins with few chromophores in their structures have very weak UV absorption. Therefore, the UV detector which is the most popular detector among these detection methods, was not adopted in CCC for separation of steroid saponins. Therefore, the evaporative light scattering detector (ELSD), a universal and non-specific detector, was used for CCC for the present study. However, the UV detector could be used in preparative RP-HPLC for the same purpose where the sensitivity was satisfactory at the wavelength of $203 \mathrm{~nm}$, because the mobile phase was transparent at this wavelength. A small volume of effluent from the outlet of the column was lost in CCC due to a flow splitter used in ELSD, whereas there was no sample wastage in preparative RP-HPLC. In addition, the cycle time was $3.5 \mathrm{~h}$ in CCC, while it was $1 \mathrm{~h}$ in preparative RP-HPLC. Considering these reasons described above, the latter approach was better than the former one.
The crude extract of total steroid saponins could directly be loaded on the CCC column, and pure compounds could be obtained in one step with the total elution volume of $400 \mathrm{ml}$. Preparative RP-HPLC separation, on the other hand, required two-step operation and pure compounds were obtained with the total elution volume of $960 \mathrm{ml}$. This clearly indicates that preparative RP-HPLC approach consumed over double amount of solvent compared to CCC. Therefore, CCC was more cost-effective than preparative RP-HPLC.

The separation efficiency was a little different, if their various aspects were compared just as the pre-paragraph mentioned. Abundant solvent with little water were used, however the mobile phrase composed water at higher in reverse preparative HPLC were applied. Therefore, so many reagents should be condensed at higher temperature and recovered, which was a time-consuming procedure. What's more, the quality of the five compounds would be loss when they were condensed and transferred from this process to another one in the two-step HPLC. At the same time, some quality of separated compounds were absorbed on the solid phrase in HPLC. Therefore, it seemed the separation efficiency in CCC method was a little higher than that in pre-HPLC. Of course, the recoveries of these five compounds revealed the similar results as less quality was lost in CCC.

As stated above, CCC and preparative RP-HPLC each have its own specific advantages: CCC can separate a large amount of crude extracts usually without pre-purification, whereas preparative HPLC produces efficient separation in a short elution time. Recently, combined use of these two methods to isolate and purify some minor and unknown components in crude samples from natural products is becoming a new and superior separation mode over other chromatographic methods due to the complementary action between these two methods [26]. In order to efficiently separate the steroid saponins with high polarity, there is an urgent need for adopting combinational method: with initial preparation preformed by CCC to enrich certain polarity bands containing the chosen targets, followed by further purification using high resolution prep-HPLC procedures with small particle size 
Citation: Zhang X, Liu J, Sun W, Ito Y (2015) Comparative Studies on Performance of CCC and Preparative RP-HPLC in Separation and Purification of Steroid Saponins from Dioscorea Zingiberensis C.H.Wright. J Steroids Horm Sci 6: 1000.150.

Page 8 of 9

ODS column, such as $5 \mu \mathrm{m}$ or $10 \mu \mathrm{m}$, the highly pure saponins could be obtained from natural products. Its most significant advantage is that almost quantitative mass balance of components and better resolution were achieved simultaneously within short separation time. Thus, it would facilitate the establishment of optimum separation conditions for almost all kinds of steroid saponins by CCC, prepHPLC, or with their combination.

\begin{tabular}{|c|c|c|}
\hline Various aspects & $\operatorname{ccc}$ & $\begin{array}{l}\text { preparative RP } \\
\text { HPLC }\end{array}$ \\
\hline Separation mechanism & Liquid-liquid mode & Liquid-solid mode \\
\hline Irreversible adsorption & None & Some \\
\hline Cycle time of each separation & Long & Short \\
\hline Choice of solvent system & Many & Few \\
\hline Solid phase types & None & Many \\
\hline Elution mode & Few & Several \\
\hline Sample preparation & Simple & Complex \\
\hline $\begin{array}{l}\text { Optimizing the chromatographic } \\
\text { condition }\end{array}$ & Complex & Complex \\
\hline Sample loading capacity & Large & Small \\
\hline $\begin{array}{l}\text { Effluent monitoring method } \\
\text { Selecting solvent system } \\
\text { Solvent consumption } \\
\text { Amplification from the analytical } \\
\text { mode } \\
\text { Separation efficiency } \\
\text { Recoveries }\end{array}$ & $\begin{array}{l}\text { Few } \\
\text { Time-consuming } \\
\text { Low } \\
\text { Relatively simple } \\
\text { A little better } \\
\text { higher }\end{array}$ & $\begin{array}{l}\text { Many } \\
\text { Relatively simple } \\
\text { High } \\
\text { Time-consuming } \\
\text { A little worse } \\
\text { Lower }\end{array}$ \\
\hline
\end{tabular}

Table 3: Comparison of CCC and preparative RP-HPLC.

\begin{tabular}{|l|l|l|l|}
\hline Parameters & CCC & RP-HPLC & $\begin{array}{l}\text { Ratio CCC/RP- } \\
\text { HPLC }\end{array}$ \\
\hline Run time/injection (min) & 210 & 60 & 3.5 \\
\hline $\begin{array}{l}\text { Mobile phase flow rate (ml } \\
\text { min-1) }\end{array}$ & 2 & 16 & 0.125 \\
\hline Operating pressure (Mpa) & 2 & 19.97 & 0.1 \\
\hline Column volumes (ml) & 300 & 60 & 5 \\
\hline Sample loading/run (mg) & 100 & 100 & 1 \\
\hline Injection volume (ml) & 10 & 2 & 5 \\
\hline Total solvent used & 420 & 960 & 0.437 \\
\hline Purity of five compounds & Over 95\% & Over 95\% & Close 1 \\
\hline Detector & ELSD & UV & - \\
\hline
\end{tabular}

Table 4: Comparison of performance parameters between CCC and RP-HPLC chromatography for $100 \mathrm{mg}$ steroid saponins separation campaigns.

\section{Conclusions}

Two approaches including CCC and preparative RP-HPLC were each successfully established for the separation and purification of steroid saponins from the same crude extract of Dioscorea zingiberensis C.H.Wright for the first time. Through comparison of the separation time and solvent consumption between these two approaches, it was found that CCC required a longer separation time with much less solvent consumption, while preparative RP-HPLC gave a much shorter separation time but with higher solvent consumption. Five steroid saponins were successfully isolated and purified from the crude extract at high purity of over $95 \%$. These methods can be further applied to isolate other steroid saponins, especially minor and unknown ones from the crude extracts of natural products.

\section{Acknowledgement}

The authors thank Prof. Zhongfu Wang of the Key Laboratory of Resource Biology and Biotechnology in western China for assistance in ESI-MS experiments, and Prof. Yong Sun of the Analysis Test Center for assistance in NMR experiments.

\section{References}

1. Li H, Ni JR (2011) Treatment of waste water from Dioscorea zingiberensis tubers used for producing steroid hormones in a microbial fuel cell. Bioresour Technol 102: 2731-2735.

2. Li H, Huang W, Wen YQ, Gong GH, Zhao QB et al. (2010) Antithrombotic activity and chemical characterization of steroidal saponins from Dioscorea zingiberensis C.H. Wright. Fitoterapia 81: 1147-1156.

3. Wang YX, Liu H, Bao JG, Hong Y, Yang ZH, et al. (2008) The saccharification-emembrane retrieval-hydrolysis (SMRH) process: a novel approach for cleaner production of diosgenin derived from Dioscorea zingiberensis. J Cleaner Production 16: 1133-1137.

4. Dong YS, Teng H, Qi SS, Liu L, Wang H, et al. (2010) Pathways and kinetics analysis of biotransformation of Dioscorea zingiberensis by Aspergillus oryzae. Biochem Eng J 52: 123-130.

5. Huang W, Zhao HZ, Ni JR., Zuo H, Qiu LL, et al. (2008) The best utilization of D. zingiberensis C.H. Wright by an eco-friendly process. Bioresour Technol 99: 7407-7411.

6. Zhang YQ, Tang LR, An X, Fu E, Ma CF (2009) Modification of cellulase and its application to extraction of diosgenin from Dioscorea zingiberensis C.H. Wright. Biochem Eng J 47: 80-86.

7. Qin Y, Wu XH, Huang W, Gong GH, Li D, et al. (2009) Acute toxicity and sub-chronic toxicity of steroidal saponins from Dioscorea zingiberensis C.H.Wright in rodents. J Ethnopharmacol 126: 543-550.

8. Qiu L, Niu H, Huang W (2011) Ultrasonic and fermented pretreatment technology for diosgenin production from Diosorea zingiberensis C.H. Wright. Chem Eng Res Des 89: 239-247.

9. Cui HY, Jia XY, Zhang X, Zhang J, Zhang ZQ (2011) Optimization of counter-current chromatography for separation of polyphenols from the extract of hawthorn (Crataegus laevigata) with response surface methodology. Sep Purif Technol 77: 269-274.

10. Xiao XH, Guo ZN, Deng JC, Li GK (2009) Separation and purification of isofraxidin from Sarcandra glabra by microwave-assisted extraction coupled with high-speed counter-current chromatography. Sep Purif Technol 68: 250-254.

11. Zhu JB, Guo XJ, Fu SP, Zhang XL, Liang XM, et al. (2010) Characterization of steroidal saponins in crude extracts from Dioscorea zingiberensis C. H. Wright by ultra-performance liquid chromatography/ electrospray ionization quadrupole time-of-flight tandem mass spectrometry. J Pharm Biomed Anal 53: 462-474. 
Citation: Zhang X, Liu J, Sun W, Ito Y (2015) Comparative Studies on Performance of CCC and Preparative RP-HPLC in Separation and Purification of Steroid Saponins from Dioscorea Zingiberensis C.H.Wright. J Steroids Horm Sci 6: 1000.150.

Page 9 of 9

12. Du QZ, Jerz G, Waibel R, Winterhalter P (2003) Isolation of dammarane saponins from Panax notoginseng by high-speed counter-current chromatography. J Chromatogr A 1008: 173-180.

13. Xin XL, Yang Y, Zhong J, Aisa HJA, Wang HQ (2009) Preparative isolation and purification of isobenzofuranone derivatives and saponins from seeds of Nigella glandulifera Freyn by high-speed counter-current chromatography combined with gel filtration. J Chromatogr A 1216: 4258-4262.

14. Shi SP, Jiang D, Zhao MB, Tu PF (2007) Preparative isolation and purification of triterpene saponins from Clematis Mandshurica by highspeed counter-current chromatography coupled with evaporative light scattering detection. J Chromatogr B 852: 679-683.

15. Chen QQ, Hu XF, Li JM, Liu P, Yang Y, et al. (2011) Preparative isolation and purification of cuminaldehyde and p-menta-1,4-dien-7-al from the essential oil of Cuminum cyminuml. by high-speed counter-current chromatography. Anal Chim Acta 689: 149-154.

16. Goetzinger W, Zhang X, Bi G, Towle M, Cherrak D, et al. (2004) High throughput HPLC/MS purification in support of drug discovery. Int J Mass spectrom 238: 153-162.

17. Chtner FF, Angelberger P, Kvaternik H, Hammerschmidt F, Simovc BP (2002) Aspects of 6-[18F]fluoro-L-DOPA preparation: precursor synthesis, preparative HPLC purification and determination of radiochemical purity. J Steinbach Nucl Med Biol 29: 477-481.

18. Vailaya A, Sajonz P, Sudah O, Capodanno V, Helmy R, et al. (2005) Exploiting $\mathrm{pH}$ mismatch in preparative high-performance liquid chromatographic recovery of ertapenem from mother liquor streams. J Chromatogr A 1079: 80-91.
19. Sajonz P, Vailaya A, Sudah O, McPherson L, Capodanno V, et al. (2006) Development of a gradient elution preparative high performance liquid chromatography method for the recovery of the antibiotic ertapenem from crystallization process streams. J Chromatogr A 1126: 365-372.

20. Yang RT, Xu DP, Tang SR, Pan FS, Zhao AM, et al. (2008) Isolation and identification of steroidal saponins from fresh rhizome of Dioscorea zingiberensis. Chinese Traditional and Herb Drugs. 4: 493-496.

21. Tang SR, Yang RT, Pan FS, Zhao AM, Pang ZJ (2007) Steroidal saponin and steroidal sapogenin in Chinese Dioscorea L. J Pla Rea Envir. 16: 64-72.

22. Yang RT, Xu DP, Tang SR, Pan FS, Zhao AM, et al. (2008) Isolation and identification of steroidal saponins from fresh rhizome of Dioscorea zingiberensis. Chin Tradition Herbal Drugs 39: 493-496.

23. Yang RT, Tong HY (2010) Research of Steroidal Saponins from the Fresh Rhizomes of Dioscorea zingiberensis. J Chin. Medicinal Materials. 33: 62-64.

24. Yang RT, Tong HY (2010) Ito Y (2005) Golden rules and pitfalls in selecting optimum conditions for high-speed counter-current chromatography. J. Chromatogr. A. 1065: 145-168.

25. Sajonz P, Natishan TK, Antia FD, Frenette R (2005) Optimization of the preparative separation of a chiral pharmaceutical intermediate by high performance liquid chromatography. J. Chromatogr. A 1089: 135-141.

26. Yao S, Luo JG, Huang XF, Kong LY (2008) Application of preparative high-speed counter-current chromatography/preparative highperformance liquid chromatography mode in rapid separation of saponins. J Chromatogr B 864: 69-77. 